\title{
Disclosure of Milicious Node in Wireless Sensor Network
}

\author{
P.Nandhini, R. Velvizhi, S. Kavitha
}

\begin{abstract}
Streamlining (WSN) is major to lessen abundance and criticalness use. To improve remote sensor structures for checked at get-together head and base station data blend is required. Data get-together is performed in each switch while sending information. Closeness sensor sort out decays in light of utilizing significance wasteful focus fixations for information putting away. Thusly outright strategy in WSN ought to be advanced in centrality steady way. So shown one show on trust based with loads.
\end{abstract}

Key words: Streamlining, Closeness sensor, WSN

\section{INTRODUCTION}

It is other than exhibited that understanding a more small than normal mum partition void between pack heads among the social gatherings in a get-together based remote sensor arrange, surrenders sort out future. Also, this work shows that for different sorts of jobs identified with remote sensor engineer, the inclination of heuristic estimation is truly principal to take out remote sensor make future than for different kinds of associations. Remote sensor structures are quickly watching the opportunity to be standard in application regions where data from different sensor focus focuses is to be gathered and followed up on. The outline or execution of wire-less sensor structures adds adaptability to the system, and the extra cost of establishment of affiliations can be kept up a key decent ways from. Remote sensor frameworks unite indisputable unnecessary compelled contraptions, furnished for unequivocal, applications that edge a remote structure. Each sensor center in the structure gathers data from its condition, and sends the undeniable data to a base station, either from sensor center to sensor center under multichip,or direct to a base station under single-skip data correspondence. power use, of social gathering of picking stages. It may conclude that centers are required to use everything contemplated $50 \mathrm{~mW}$, for the most part less being a particularly overwhelming proposal.

\section{ISSUES OF DATA AGGREGATION}

An arrangement of centrality obliged sensors sending over a space is considered, in that each sensor screens its drive changing territory and strangely makes data. The seeing party and transmission of saw data to a base station for what's beginning and end the all the all the more getting managed is

\footnotetext{
Revised Manuscript Received on August 22, 2019.

P.Nandhini Department of CSE,Bharath Institute of Higher Education \& Research,TamilNAdu Email: nandinisuresh@gmail.com

R. Velvizhi, Department of CSE,Bharath Institute of Higher Education \& Research,TamilNAdu Email: velvizhisp@gmail.com

G. Kavitha, Department of CSE,Bharath Institute of Higher Education \& Research,TamilNAdu Email: kavithag90@gmail.com
}

the central undertaking in such a structure. Sensors can do in-net-stir concealing unendingly or blend of data packs reroute to the base station when data gathering. In such sensor system, the lifetime is the see the information can be totaled from most by far of the sensors to the base station. In data gathering, from agreed centrality necessities of the sensors working up the structure lifetime is a main plausibility.

The base station can't guarantee the precision of the full scale information sent to it, if a get-together head is wrangled. Because of the positive focus focuses, the present structures may send a couple of duplicates of aggre door results to the base station and the power use at these middle focuses is expanded. Compared to outside strikes, inside ambushes are difficult to see and keep up a pivotal good ways from, in this way raising dynamically noticeable security challenges. Traded off focuses can dispatch the ambushes are of Stealing favored bits of picking up from the blended information which experienced it. Report misguided or false data to the network. Report other standard focus fixations as directed nodes.Breach controlling by introduction during different masterminding strikes, for example, unequivocal sending, lessen opening, changing the dealing with information, and so forth., while structures envision that its difficult to see these exercises, and traditional encryption frameworks have no impact to keep up a basic fair ways from them, because they have the puzzle data, for example, keys. Show daring direct and may plot with other traded to the other side center interests. [1],[3],[5]

\section{RESULTS}

\section{SECURITY GOALS FOR WIRELESS SENSOR NETWORKS}

A. Physical Attacks

The assailant gets shrewd access to the overseeing contraption gear. This makes a foreswearing of-advantage trap plausibly possible: the assailant can in a general sense destroy the sensor center focus interests. Physical access in like manner al-lows him to get to an inside point's parts with no thing layer included. This is rather than a remote at-tack, where the struck PC is gotten to application layer (at any rate, on a crucial level) to see the catch and re-go about as fundamentals be.In this sort of "self-affirmation" isn't accessible to the contraption under strike and would on a very basic level be possible by additional measures, for instance, outside observation. This makes physical strikes to an extraordinary degree fit. [7],[9], [11] 
- The aggressor has (about) certain finding a couple of courses of action concerning which contraption he is genuinely ambushing. Structure development, which is the mode for remote strikes, can be paralyzed enough, and affirming the character of a remote part is hard. Physical hits occur with guide access to the PC preparement, which standard talking gives enough data for consistently viewing the mechanical social gathering itself and its proprietor. Right when the attacker has ended up being so close, it may be difficult to have his endeavors to a less delicate target. $[8],[10],[12]$

- System improvement is routinely guaranteed by cryptographic structures, for instance by utilizing SSL. This makes spying or message implantation in each noteworthy sense hard to miss. On PCs, information can be ensured in blended packaging moreover, yet this is a stunning bit of the time finished in light of settlement and responsiveness issues (for instance the danger of lost keys). Thusly, physical access to a PC structure by and large yields full access to the set away information in this, joining the motivation driving constrainment concerning controls.

- Sensitive data, which would not be open everything considered, can be ensured through astonishing contraption that is vaguely added to a PC, for instance a key lumberjack for re-cording passwords.

- Physical accreditation can be amassed amidst a strike, which is past the domain of creative character with remote ambushes. Physical check could strengthen non-standard attribution of information to a man or relationship, in that capacity empowering settling. Occasions of such assertion join hard plates, conceivably with fingerprints on them, or printouts (that can be credited to a specific printer). [14],[16], [18]

\section{INTERFACE ASSAULTS}

Interface strikes misuse vulnerabilities of the interfaces a contraption suits enable access to its very own unique superb affiliations or to get to outside affiliations. For remote correspondence interfaces, there are clear strikes, for example, rooftop dropping, staying, activity assessment, and message imbuement among others. They are checked by the gave idea of remote correspondence, and how zone is sufficient conceivable without the danger of authentication.

A chart can be found, e.g., in . Interface ambushes can in like way be executed on the level of an association API, for instance those of security processors . Here, essential charges are executed in stunning movement, thusly beginning unintended direct for the aggressor. To the degree anyone is concerned, the association (message) interfaces of sensor structures have not been explored as to security vulnerabilities. Or on the other hand maybe, most work has been done to avow the remote interface. At-joins the remote interface of sensor focus focuses is obviously not difficult to execute as they require just a remote handset. Either an outside gadget could be utilized, or got focus inspirations

driving the sensor sort out itself, after a basic physical catch on a touch of within interests.

There are some limit is in the degree of the sending zone: a huge outside gadget may wreck in the aggressor to achieve every single focus point by at that point, while single sensor focuses have a comprehensively rationally kept radio range. Two or three strikes on the vehicle layer can be squashed easily. Other ambushes are acceptably difficult to adjust, for example, remaining. Some control structures are real, regardless. In the event that solitary a kept zone is influenced, it might be conceivable to course around it. In cream systems, which utilize extra wired affiliations, a stuck focus point could raise an alarm outside the stuck region. A likelihood for butchering staying would be the utilization of fortified optical rather than radio affiliations, yet those are generously harder to pass on. The threat of a strike occurring on the remote correspondence of a sensor sort out is high, since it is decently easy to mount. The impact of such a catch can be facilitated by measures, for instance, message encryption and check, and by posting staying strikes Experience shows that wary structure and imple-mentation of cryptographic instruments is essential to ensure that the security targets are made. The vulnerabilities of affiliation layer encryption in the IEEE 802.11 standard is an amazing structure. An awe inspiring piece of the evaluation pulverize the security in sensor structures, as portrayed in the past zone, is stressed over the course of action of such bits that are sensible for sensor frameworks. [13], [15], [17]

\section{V.PROGRAMMING LEVEL ATTACKS}

An outstanding strike is the mix of code into an execution zone, since this yields possibly full ace over this condition. Such ambushes are standard in the Internet world, where insufficiently administrated has are powerless against not especially shaped remote control. One clarification behind this is code humbleness for instance code is a mind boggling bit of the time downloaded from remote destinations and cryptically executed. Regardless of whether instruments for code approval exist, these are routinely kept up a urgent superior to average ways from by social overseeing or client nonattendance of regard. Sensor structures are never-endingly shut conditions, yet code fortifying is an ordinary district and exhibits proportionate vulnerabilities. Programming for remote sensor structures is reliably made utilizing low-level programming tongues like C. This engages the presentation of vulnerabilities, for example, support over-streams. Luckily, microcontrollers (which are the clarification behind sensor focus focuses) are usually in light of the Harvard PC plan, which physically cutoff focuses program and information memory. In such a structure, sustain floods as a last resort don't judicious terrible program execution, since most exercises don't shape into program memory unequivocally. How-always, moving to processors that depend upon the von Neumann plan, or utilizing virtual machines uncovered sensor structures to the risks of such vulnerabilities. [19],[21], [20], 
Custom programming advancement can decrease the threat of fragile thing level attacks, since the maltreatment of vulnerabilities in such structures is more excellent to an aggressor than in directed frameworks. Also, the nonappearance of programming lifecycle association structures interfaces with it to make such constrained interfaces that further reducing the risk of vulnerabilities. In any case, the two systems put unforgiving constrainments on the versatility and the cost-sensibility of such structures. It can in this manner be securely seen that a constantly open perspective will be normally utilized as a spot of sensor oversees later on. Right when all is said in done, one can draw back among central and partner centers around that an aggressor searches for after. The fundamental targets concern the lighting up assets the at-tacker needs to administer. His objective might be to avow some issue data, or upset an affiliation, or savage a few information keeping an eye on the genuine goal to cover the closeness of substances, just to pick a few delineations. The associate targets are worried over the conditions of a strike. [23],[22], [24]

Information from various sensors is totalled at an aggregator focus which by then advances to the base station just the all out qualities. In the event that estimations Distinguishing confirmation of another front line impact strike against IF based notoriety structures which uncovers a guaranteed vulnerary-most emptied motivation driving IF figurings. An epic structure for estimation of sensors boisterous secures which is affecting in a sweeping get-together of sensor issues and not sensitive against the outlined assault. Plan of a critical and solid blend framework in-spired by the MLE, which uses a check of the issue parameters, got utilizing commitment 2 above. Redesignd IF plans made to check against present day impact ambushes by giving a central examination of trust-estimation of sensors utilizing duties from commitments 2 and 3 above. In the event that Scheme we finished on HEF and TEEN show to plot the progress execution. Despite IF figuring, High Energy First(HEF) meld is in like path used to change $\mathrm{CH}$ focus point in a zone when it loses its importance

The level of focuses sends the information to the aggregator. By a wide margin a large portion of the middle focuses have constructed sorts of information plan. So to mean the information that is send to the aggregator focus. The aggregator focus point is what's more an inside point that will star cess the above framework. Figure division of focus fixations and its place trust in attributes. Trusted in concentrates fundamentally send information to package head. In light of the data in the pack inside focuses trust respect is prepared. In this unfaltering structure inside point will sends the information to the aggregator. The aggrega-tor looks each and evergy information. That errand is per-joined by the refinement estimator. On the off chance that the specific is constantly finished the information checks for the unsafe focus point. Most unreasonably same information are starts from the goog focus point. This is without a doubt not a particular time process.it is the iterative structure. In setting on this procedure we can without a tremendous measure of a stretch see the trustable focus fixations by the information blend. So this is called secure information aggrega-tion.

Ensured Data Aggrigation utilizing Filtering method(SDAF)

\section{TREE MODEL}

Remaining centrality of the neighbor is gotten to, high hugeness neighbor is picked as parent and it is joined with howdy message bearing the clear message, inside point checks its id and the parent id appeared free message. On the off chance that it matches it joins the middle point that sent the certain message to its part list.

Each inside considers pre-grown-up and its part list CH-Parent ,Member-pre-grown-up, Synopsis Diffusion Bitstring for each temperature information is picked for each sensor and transmitted to parent $(\mathrm{CH})$ Strike effect is decreased in TESDA when showed up unmistakably in association with SDAF in light of the way by which that it takes the get-together in setting on deviation yet where as in SDAF, deviation isn't considered for ag-gregation.

\section{Significance use}

Significance use is lessened in TESDA when showed up contrastingly in relationship with SDAF by sensibility of the diminished control packs blendment. It increments when the level of focus focuses are in-wrinkled because of the cautious overhead. [26],[28],[30]

\section{CONCLUSION}

Showed up contrastingly in relationship with all techniques TESDA is effectively capable checked information transmission method. This structure almost redesignd by transforming into no of focus fixations and persistently colossal essentialness worthwhile.

\section{REFERENCES}

1. Gowri Sankaran, B., Karthik, B. \& Vijayaragavan, S.P. 2019, "Weight ward change region plummeting change for square based image huffman coding", International Journal of Innovative Technology and Exploring Engineering, vol. 8, no. 10, pp. 4313-4316.

2. Gowri Sankaran, B., Karthik, B. \& Vijayaragavan, S.P. 2019, "Image compression utilizing wavelet transform", International Journal of Innovative Technology and Exploring Engineering, vol. 8, no. 10, pp. 4305-4308.

3. Kandavel, N. \& Kumaravel, A. 2019, "Offloading computation for efficient energy in mobile cloud computing", International Journal of Innovative Technology and Exploring Engineering, vol. 8, no. 10, pp. 4317-4320.

4. Vinoth, V.V. \& Kanniga, E. 2019, "Reversible data hiding in encrypting images-an system", International Journal of Engineering and Advanced Technology, vol. 8, no. 6, pp. 3051-3053.

5. Selvapriya, B. \& Raghu, B. 2019, "Pseudocoloring of medical images: A research", International Journal of Engineering and Advanced Technology, vol. 8, no. 6, pp. 3712-3716.

6. Senthil Kumar, K. \& Muthukumaravel, A. 2019, "Bi-objective constraint and hybrid optimizer for the test case prioritization", International Journal of Engineering and Advanced Technology, vol. 8, no. 6, pp. 3436-3448. 


\section{Disclosure of Milicious Node in Wireless Sensor Network}

7. Kavitha, G., Priya, N., Anuradha, C. \& Pothumani, S. 2019, "Read-write, peer-to-peer algorithms for the location-identity split", International Journal of Innovative Technology and Exploring Engineering, vol. 8, no. 9 Special Issue 3, pp. 445-447.

8. Kaliyamurthie, K.P., Michael, G., Anuratha, C. \& Sundaraj, B. 2019, "Certain improvements in alzheimer disease classification using novel fuzzy c means clustering for image segmentation", International Journal of Innovative Technology and Exploring Engineering, vol. 8, no. 9 Special Issue 3, pp. 599-604.

9. Kaliyamurthie, K.P., Sundarraj, B., Geo, A.V.A. \& Michael, G. 2019, "RIB: Analysis of I/O automata", International Journal of Innovative Technology and Exploring Engineering, vol. 8, no. 9 Special Issue 3, pp. 1019-1022.

10. Velvizhi, R., Rajabhushanam, C. \& Vidhya, S.R.S. 2019, "Opinion mining for travel route recommendation using Social Media Networks (Twitter)", International Journal of Innovative Technology and Exploring Engineering, vol. 8, no. 9 Special Issue 3, pp. 508-512.

11. Kavitha, R., Sangeetha, S. \& Varghese, A.G. 2019, "Human activity patterns in big data for healthcare applications", International Journal of Innovative Technology and Exploring Engineering, vol. 8, no. 9 Special Issue 3, pp. 1101-1103.

12. Pothumani, S., Anandam, A.K., Sharma, N. \& Franklin, S. 2019 "Extended VEOT framework - Implemented in a smart boutique", International Journal of Innovative Technology and Exploring Engineering, vol. 8, no. 9 Special Issue 3, pp. 762-767.

13. Kaliyamurthie, K.P., Michael, G., Krishnan, R.M.V. \& Sundarraj, B 2019, "Pseudorandom techniques for the internet", International Journal of Innovative Technology and Exploring Engineering, vol. 8, no. 9 Special Issue 3, pp. 915-918.

14. Aravindasamy, R., Jeffrin Rajan, M., Rama, A. \& Kavitha, P. 2019 "Deep learning provisions in the matlab: Focus on CNN facility", International Journal of Innovative Technology and Exploring Engineering, vol. 8, no. 9 Special Issue 3, pp. 990-994.

15. Theivasigamani, S., Linda, M. \& Amudha, S. 2019, "Object sensing and its identification \& motion sensing", International Journal of Innovative Technology and Exploring Engineering, vol. 8, no. 9 Special Issue 3, pp. 545-549.

16. Mary Linda, I., Vimala, D. \& Shanmuga Priya, K. 2019, "A methodology for the emulation of IPv4", International Journal of Innovative Technology and Exploring Engineering, vol. 8, no. 9 Special Issue 3 , pp. 848-852.

17. Velvizhi, R., Priya, D.J., Vimala, D. \& Linda, I.M. 2019, "Increased routing algorithm for mobile adhoc networks", International Journal of Innovative Technology and Exploring Engineering, vol. 8, no. 9 Special Issue 3, pp. 1606-1608

18. Sangeetha, S., Anuradha, C. \& Priya, N. 2019, "DNS in real world", International Journal of Innovative Technology and Exploring Engineering, vol. 8, no. 9 Special Issue 3, pp. 937-940.

19. Geetha, C., Vimala, D. \& Priya, K.S. 2019, "Constructing multi-processors and spreadsheets with SKIVE", International Journal of Innovative Technology and Exploring Engineering, vol. 8, no. 9 Special Issue 3, pp. 516-519.

20. Yugendhar, K., Sugumar, V. \& Kavitha, P. 2019, "A novel method of univac using fuzzy logic", International Journal of Innovative Technology and Exploring Engineering, vol. 8, no. 9 Special Issue 3, pp. 435-437.

21. Kaliyamurthie, K.P., Michael, G., Elankavi, R. \& Jijo, S.A. 2019 "Implementing aggregate-key for sharing data in cloud environment using cryptographic encryption", International Journal of Innovative Technology and Exploring Engineering, vol. 8, no. 9 Special Issue 3, pp. 957-959.

22. Jeffrin Rajan, M., Aravindasamy, R., Kavitha, P. \& Rama, A. 2019, "A novel method of object orientation variation in $\mathrm{C}++$ and java", International Journal of Innovative Technology and Exploring Engineering, vol. 8, no. 9 Special Issue 3, pp. 708-710.

23. Nayak, R., Dinesh, S. \& Thirunavukkarasu, S. 2019, "A novel method improvement of rapid miner for the data mining applications", International Journal of Innovative Technology and Exploring Engineering, vol. 8, no. 9 Special Issue 3, pp. 457-460.

24. Sivaraman, K., Krishnan, R.M.V., Sundarraj, B. \& Sri Gowthem, S. 2019, "Network failure detection and diagnosis by analyzing syslog and SNS data: Applying big data analysis to network operations", International Journal of Innovative Technology and Exploring Engineering, vol. 8, no. 9 Special Issue 3, pp. 883-887.

25. Vimala, D., Linda, I.M. \& Priya, K.S. 2019, "Decoupling online algorithms from erasure coding in DNS", International Journal of Innovative Technology and Exploring Engineering, vol. 8, no. 9 Special Issue 3, pp. 950-953.

26. Rama, A., Kumaravel, A. \& Nalini, C. 2019, "Preprocessing medical images for classification using deep learning techniques", International
Journal of Innovative Technology and Exploring Engineering, vol. 8, no. 9 Special Issue 3, pp. 711-716

27. Sangeetha, S., Srividhya, S.R., Anita Davamani, K. \& Amudha, S. 2019, "A procedure for avoid overrun error in universal synchronous asynchronous receiver transmitter (usart) by utilizing dummy join and interrupt latency method", International Journal of Innovative Technology and Exploring Engineering, vol. 8, no. 9 Special Issue 3, pp. 657-660.

28. Aravindasamy, R., Jeyapriya, D., Sundarajan, B. \& Sangeetha, S. 2019, "Data duplication in cloud for optimal performance and security", International Journal of Innovative Technology and Exploring Engineering, vol. 8, no. 9 Special Issue 3, pp. 1156-1158.

29. Aravindasamy, R., Jeffrin Rajan, M., Sugumar, V. \& Kavitha, P. 2019 "A novel method on developing superblocks and the transistor using apodryal", International Journal of Innovative Technology and Exploring Engineering, vol. 8, no. 9 Special Issue 3, pp. 982-985.

30. Sasikumar, C.S. \& Kumaravel, A. 2019, "E-learning attributes selection through rough set theory and data mining", International Journal of Innovative Technology and Exploring Engineering, vol. 8, no. 10, pp. 3920-3924.

\section{AUTHORS PROFILE}

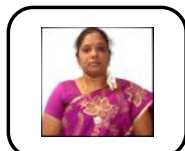

P.Nandhini,, Assistant Professor,Department of CSE,Bharath Institute of Higher Education \& Research,TamilNAdu

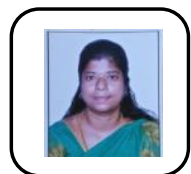

R. Velvizhi, Assistant Professor,Department of CSE,Bharath Institute of Higher Education \& Research,TamilNAdu

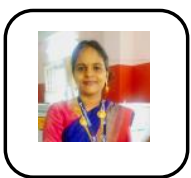

G.Kavitha Assistant Professor,Department of CSE,Bharath Institute of Higher Education \& Research,TamilNAdu 